Weert, J.C.M. van, Noort, G. van, Bol, N., Dijk, L. van, Tates, K., Jansen, J. Tailored information for cancer patients on the Internet: effects of visual cues and language complexity on

\begin{tabular}{|l|l|}
\hline $\begin{array}{l}\text { Postprint } \\
\text { Version }\end{array}$ & 1.0 \\
\hline $\begin{array}{l}\text { Journal website } \\
\text { Pubmed link }\end{array}$ & $\underline{\text { http://dx.doi.org./10.1016/j.pec.2011.04.006 }}$ \\
\hline DOI & $\underline{\text { http://www.ncbi.nlm.nih.gov/pubmed/21550757 }}$ \\
\hline
\end{tabular}

This is a NIVEL certified Post Print, more info at http://www.nivel.eu

\title{
Tailored information for cancer patients on the Internet: Effects of visual cues and language complexity on information recall and satisfaction
}

\author{
Julia C.M. VAN WEERT ${ }^{A,}$, , GUdA VAN NOORT ${ }^{A}$, NADINE BOL ${ }^{A}$, LISET VAN DIJK ${ }^{B}$, KIEK \\ TATES $^{C}$ AND JESSE JANSEN ${ }^{D}$ \\ ${ }^{a}$ Amsterdam School of Communication Research ASCoR, Department of Communication \\ Sciences, University of Amsterdam, Amsterdam, The Netherlands \\ ${ }^{\mathrm{b}}$ Netherlands Institute for Health Services Research (NIVEL), Utrecht, The Netherlands \\ ${ }^{c}$ Tilburg University, Department of Communication and Information Sciences, Tilburg, The \\ Netherlands \\ ${ }^{d}$ Screening and Test Evaluation Program, Centre for Medical Psychology and Evidence \\ Based Decision Making, Sydney School of Public Health, University of Sydney, New South \\ Wales, Australia
}

\begin{abstract}
Objective This study was designed to investigate the effects of visual cues and language complexity on satisfaction and information recall using a personalised website for lung cancer patients. In addition, age effects were investigated.

Methods An experiment using a 2 (complex vs. non-complex language) $\times 3$ (text only vs. photograph vs. drawing) factorial design was conducted. In total, 200 respondents without cancer were exposed to one of the six conditions.

Results Respondents were more satisfied with the comprehensibility of both websites when they were presented with a visual cue. A significant interaction effect was found between language complexity and photograph use such that satisfaction with comprehensibility improved when a photograph was added to the complex language condition. Next, an interaction effect was found between age and satisfaction, which indicates that adding a visual cue is more important for older adults than younger adults. Finally, respondents who were exposed to a website with less complex language showed higher recall scores.

Conclusion The use of visual cues enhances satisfaction with the information presented on the website, and the use of non-complex language improves recall.

Practice implications The results of the current study can be used to improve computer-based information systems for patients.
\end{abstract}

\section{INTRODUCTION}

In recent decades, the Internet has become a widely used medium to access health-related information. Worldwide, more than 12 million sites that contain health information are used 
Weert, J.C.M. van, Noort, G. van, Bol, N., Dijk, L. van, Tates, K., Jansen, J. Tailored information for cancer patients on the Internet: effects of visual cues and language complexity on

information recall and satisfaction. Patient Education and Counseling: 2011, 84(3), 368-378

each day [1]. Cancer is among the top three diseases that patients research on the Internet [2]. One of the main reasons cancer patients use the Internet is to search for informational support, which can be explained as the need for information on cancer or its treatment [3]. Because it appears that cancer patients consistently have unmet information needs [4], providing high-quality information on the Internet in addition to improving patient-provider communication may help to meet these needs [5]. Indeed, research has demonstrated that cancer patients who use the Internet to search for information about their illness are better able to cope with the illness [6] and feel better informed and better prepared [7]. This result suggests that website use may improve patient understanding and recall of cancer-related information i.e., their ability to understand and reproduce the message. In turn, patients' accurate recall of information, is likely to improve outcomes in terms of better compliance [8] and [9], more adequate disease management and decreased anxiety [10] and [11]. In addition, there is a robust relationship between positive affect and memory such that when messages evoke positive feelings (including satisfaction), they cue memories that have previously been associated with positive affect [12]. This concept supports the idea that website satisfaction is important to attract attention, increase information processing and improve information recall.

Although the Internet is acknowledged as a powerful source of information for patients, individuals are not always satisfied with the health information that they find online. First, many people struggle to find the specific information that they need [13]. This challenge may be due to an information overload on the Internet [14], which makes it difficult for patients to find what they are looking for and to filter out the information that is relevant to their specific situation [6]. To overcome this problem, a new information strategy has been proposed, which is the tailored information strategy [15] and [16]. Tailored information uses individual characteristics to create a personalised message. Empirical health communication research confirms that tailored interventions are more effective than standard information with respect to, for instance, perceived relevance, information recall and behaviour change [17], [18], [19], [20], [21] and [22].

Incomprehensibility is a second cause of dissatisfaction with online health information. Health websites often use complex medical terminology, and much of the medical information that is targeted towards patients on the Internet is written at a reading level that is too high to be easily understood by many patients [23], [24] and [25]. This suggests that while tailored websites may greatly improve the relevance of information, the information might still be incomprehensible to many health information seekers. This seems to be the case for personalised websites as well, which have recently emerged as a form of tailored information. Personalised websites are set up to meet the specific information needs of individual patients and contain specific disease and treatment information for the exclusive use of each patient [26]. It is important not to confuse personalised websites with automated systems that deliver personalised health information based on algorithms, which is a different form of tailored interventions [16]. A recent example of a personalised website is the website designed for cancer patients at the Netherlands Cancer Institute-Antoni van Leeuwenhoek Hospital (NCI-AVL). Patients obtain a login name and a password that provide them with in-home access to their personalised website. The website provides specific information on the diagnostic tests and treatments that they will receive. A pilot study among 22 students confirmed that the comprehensibility of this website was not optimal, and the following recommendations for improvement were made: (1) the language should be simplified and (2) images should be used to complement textual information. Therefore, the aim of this study was to test whether reducing language complexity (textual health information) and using images or visuals cues (graphical health information) can increase patients' satisfaction with a personalised website. We distinguished two subdimensions of website satisfaction, i.e., 'satisfaction with comprehensibility' and 'satisfaction with attractiveness', which refer to the textual and graphic information on the website, respectively. Because the primary purpose of tailored online health information is to 
Weert, J.C.M. van, Noort, G. van, Bol, N., Dijk, L. van, Tates, K., Jansen, J. Tailored information for cancer patients on the Internet: effects of visual cues and language complexity on

information recall and satisfaction. Patient Education and Counseling: 2011, 84(3), 368-378

inform patients [7] and because the literature suggests that the addition of visual information will result in cognitive gain and improved recall [27], the effects on patient recall of online health information were also be examined.

\section{THEORY AND HYPOTHESES}

Message comprehensibility increases the recipient's opportunity to process information, which might result in improved cognitive responses, such as information recall [28], [29], [30] and [31]. The expected positive relationship between comprehensible information and recall scores is supported by numerous health communication studies, which report that noncomplex or easy-to-read texts are effective in improving patients' understanding and recall of information [32], [33], [34], [35], [36], [37], [38] and [39]. Consequently, providing comprehensible text has often been recommended to enhance adequate processing, understanding and recall of information among patients (e.g., [8], [40] and [41]). Therefore, the following hypothesis was formulated.

H1 The use of non-complex language (vs. complex language) on a website has a positive effect on information recall.

Next, this study examined whether textual information on a health website benefits from added visual information. Research in several domains, such as psychology, education, and marketing, suggests that pictures and text may serve different functions that affect both affective and cognitive processes (see Levie and Lentz [42] for a review). Various theories (e.g., dual coding theory [43] and the cognitive theory of multimedia learning [44]) state that two modes of presentation, graphic and verbal, are better than one, and empirical research demonstrates that websites that display images that complement the textual information are more comprehensible [45]. One explanation for this effect is that visual information is perceived as more vivid than text-only information. Vividness is defined as 'the representation richness of a mediated environment as defined by its formal features' (p. 81) [46]. Vivid information appeals to the senses and is more likely to stimulate cognitive elaboration because it is more interesting and prompts a more elaborate encoding process [47]. Marketing communication studies support the notion that adding vivid visual information enhances users' understanding of an online communicated message [48]. Health communication research also has found positive effects of labelled pictures in print materials on information recall [40], [49], [50] and [51]. These results have recently been confirmed by Choi and Bakken [52], who found that the inclusion of visuals on websites improved users' understanding of the educational text. Thus, the following hypothesis was formulated.

H2 The presence of a labelled visual cue (vs. text only) on a website has a positive effect on information recall.

Prior research suggests that the inclusion of visual information on websites not only results in improved cognitive processes but also affects website evaluations. For example, in the context of commercial websites, it has been demonstrated that vivid information such as virtual tours [53] and animations [54] and [55] positively influenced users' attitudes towards the website. Correspondingly, the current study hypothesised that health websites that provide information in combination with complementary visual cues will enhance people's satisfaction with the website content. In the domain of health communication, research on the effects of using visual cues on information satisfaction is scarce and does not focus on online communication. One study found that a brochure that used visuals to illustrate the written text was evaluated more positively than those without visuals [38]. The same effect might hold true for websites. A recent study showed that different types of visuals on a health website were well accepted by users [52]. Although this study did not investigate the effect of visual cues on website satisfaction, this might result in improved satisfaction. Thus, the following hypothesis was formulated. 
Weert, J.C.M. van, Noort, G. van, Bol, N., Dijk, L. van, Tates, K., Jansen, J. Tailored information for cancer patients on the Internet: effects of visual cues and language complexity on

information recall and satisfaction. Patient Education and Counseling: 2011, 84(3), 368-378

H3 The presence of a labelled visual cue (vs. text only) on a website has a positive effect on website satisfaction.

In research on visual cues, it has been further suggested that different types of visual cues are not equally effective [56]. Some health information studies reported that (line) drawings are most effective in facilitating comprehension [57] and [58] while a recent study emphasised that the use of concrete and realistic visual cues, such as photographs, would maximise comprehension [52]. Photographs might be perceived as more realistic. Empirical research has demonstrated that low- (vs. high-) fidelity, i.e., realistic and vivid, images on commercial websites enhanced user memory [59]. However, high-fidelity images, such as photographs, might include irrelevant details that are likely to distract the user from essential information [24] and [52]. Nevertheless, taking into account Houts et al.'s [40] conclusion that simple visual cues are most effective, it can be assumed that photographs are more effective than drawings, but only if they are not too detailed. Moreover, because the literature suggests that vivid information affects both affective and cognitive processes, the current study argues that patients who visit a tailored website with a photograph (vs. drawing) are more satisfied with the website and retain more of the health information. This resulted in the following hypotheses.

H4 The presence of a labelled photograph on a website has a more positive effect on website satisfaction than the presence of a labelled drawing.

H5 The presence of a labelled photograph on a website has a more positive effect on information recall than the presence of a labelled drawing.

We mentioned that comprehensive information is processed more deeply, which might result in not only improved information recall but also greater satisfaction with the information (i.e., attitudes [16], [28] and [29]). For example, product information that is perceived as more clear is evaluated more positively [60]. Illustrations usually enhance learner enjoyment and can be used to evoke affective reactions, but words can also contribute to affective objectives [42]. This is important because positive affect is supposed to enhance memory storage and information recall [12] and because visual cues and text may reinforce each other. In particular, visual cues will improve patients' comprehension of medical information when the visual cue complements the text [42] and [61]. To help people understand the facts and ideas that are represented in pictures, language simplification may also play an important role [40]. This indicates that the combination of non-complex language with visual cues will provide the best results in terms of information recall. This idea is supported by Choi and Bakken [52], who reported that appropriate visual cues combined with simplified text were the most effective way to deliver health care information. This concept might hold for website satisfaction and for information recall. Therefore, we formulated the following hypotheses.

H6 The presence of non-complex language combined with a visual cue on a website has a more positive effect on website satisfaction than the presence of complex language combined with a visual cue or the presence of text only (complex or non-complex).

H7 The presence of non-complex language combined with a visual cue on a website has a more positive effect on information recall than the presence of complex language combined with a visual cue or the presence of text only (complex or non-complex).

Cancer is a disease that often affects older individuals [62]. Tailored research-based messages are supposed to have a greater likelihood of being received by older cancer patients than the general messages that are currently delivered [63], possibly because older people prefer to invest their cognitive resources in goal-relevant activities [64]. Older people also give more initial attention to positive features than to negative ones [65], which indicates that visual cues may attract more attention and result in greater website satisfaction than text only for older people, provided that the visual cue does not evoke negative 
Weert, J.C.M. van, Noort, G. van, Bol, N., Dijk, L. van, Tates, K., Jansen, J. Tailored information for cancer patients on the Internet: effects of visual cues and language complexity on

information recall and satisfaction. Patient Education and Counseling: 2011, 84(3), 368-378

emotions. Moreover, earlier studies have shown that visual information is more robust in situations in which audiences lack literacy skills [66] and [67]. Many studies have concluded that due to age-related declines in cognitive abilities such as working memory, older people may not have the literacy skills necessary to fully understand health information [68] and [69], and there is evidence for increased memory of visual cues among older adults [70]. Consequently, the use of visual cues (compared to text only) is expected to reduce demands on working memory [61], [71] and [72] and therefore may have more positive effects on older people's information recall than on that of younger people. Given the information mentioned above, the use of visual cues is expected to improve older people's satisfaction. Thus, the following hypotheses were formulated.

H8 The presence of a labelled visual cue (vs. text only) on a website has a more positive effect on older people's website satisfaction than on younger people's website satisfaction.

H9 The presence of a labelled visual cue (vs. text only) on a website has a more positive effect on older people's information recall than on younger people's information recall.

\section{METHOD}

\subsection{Design}

The experimental study involved a 2 (complex vs. non-complex language) $\times 3$ (text only vs. labelled photograph vs. labelled drawing) between-subjects factorial design (see Fig. 1). The participants were randomly assigned by a computer to one of the six conditions. A page of an existing website, i.e., the personalised website of NCI-AVL, was used with short and global information on surgeries for the treatment of lung cancer, such as segment resection, and more specific information regarding the surgery that the 'owner of the website' was designated to receive, in this case a wedge excision. In total, six different versions of this page were created that differed in the level of language complexity and image use while the amount and content of the information was kept constant (see pre-tests for development of stimulus materials).

\section{[FIGURE 1]}

\subsection{Procedure}

The participants $(\mathrm{N}=200)$ were selected by ten students who were enrolled in a research seminar. Each student recruited 20 participants from his own social network. The aim was to recruit a sample of participants that represented a range of educational backgrounds and ages. The inclusion criteria were as follows: (1) aged 18 years or older, (2) able to read and write in Dutch, (3) not being a medical professional, and (4) not diagnosed with lung cancer. Participants were not medical professionals or (lung) cancer patients because we expected that the knowledge and experience of these groups could influence outcomes, especially information recall. After giving informed consent, the participants were approached by email and asked to complete an online questionnaire. A computer first randomly assigned the participants to one of the six conditions, and the participants were then exposed to an online questionnaire. After reading a general introductory text, the participants received questions on background characteristics, coping style and knowledge. Next, the participants were required to view one of the six websites and were asked to read the information carefully. The participants were instructed that after viewing the website, they would be asked questions on the content of the website and that they would not be able to return to a previous screen. Because the duration of viewing a website is expected to affect information retention [73], the time spent on the website was measured. After reading the website and clicking the 'next' button, the recall questionnaire appeared on the screen (see measurements). Next, the website was displayed again, but this time, the participants were instructed to focus on the feelings and thoughts that were elicited when they looked at the 
Weert, J.C.M. van, Noort, G. van, Bol, N., Dijk, L. van, Tates, K., Jansen, J. Tailored information for cancer patients on the Internet: effects of visual cues and language complexity on

information recall and satisfaction. Patient Education and Counseling: 2011, 84(3), 368-37

website to provide their opinion. This was followed by a satisfaction questionnaire and a manipulation check (see measurements).

\subsection{Pre-tests}

In this study, several pre-tests were conducted among students to develop the stimulus materials with regard to visual cues and language complexity.

\subsubsection{Selection of visual cues}

First, the researchers selected two different drawings of the lungs, and ten students were asked to evaluate the extent to which the drawings matched the text on a 7-point scale (e.g., $1=$ does not clarify the text at all, $7=$ completely clarifies the text $)(3$ items; Cronbach's $\alpha=0.92$ ). Using t-statistics, one of the drawings appeared to score significantly higher than the other $(\mathrm{M}=5.70, \mathrm{SD}=0.94$ vs. $\mathrm{M}=3.40, \mathrm{SD}=0.77, \mathrm{p}<0.001)$, thus we selected the higher scoring drawing. Regarding the photograph, we found only one picture that we considered appropriate for the website, and we chose this picture for the additional pretests.

\subsubsection{Pre-test comprehensibility}

Next, to test whether the visual cue (vs. text only) improved the perceived understanding of the text, another group of 33 students was exposed to either the original text with no visual cue, the original text with the selected photograph, or the original text with the selected drawing. The students were asked to assess the extent to which the text was easy to understand on a 7-point semantic differential scale (e.g., $1=$ difficult, 7 = easy; $1=$ unclear, $7=$ clear) composed of five items (Cronbach's $\alpha=0.81$ ). Unexpectedly, the results showed no significant differences between the original text $(\mathrm{M}=4.48, \mathrm{SD}=0.86)$, text with the photograph $(\mathrm{M}=4.33, \mathrm{SD}=0.79)$ and text with the drawing $(\mathrm{M}=4.27, \mathrm{SD}=0.54)$. This may be due to the fact that the visuals were presented as a medical representation of the lungs (where left and right are reversed). The participants reported that this reversal confused them because the text contained information that specifically referred to anatomy of the right and the left lung. We then repeated the pre-test by exposing 14 other students to the text with a non-medical representation photograph. This process resulted in a mean score for comprehensibility of $5.73(\mathrm{SD}=0.88)$, which was significantly higher than the original score on text only $(\mathrm{M}=4.48, \mathrm{SD}=0.86, \mathrm{p}<0.001)$. Therefore, both the photograph and the drawing were presented in the non-medical manner.

\subsubsection{Pre-test vividness}

A final pre-test examined whether the three visual conditions differed in the level of vividness, i.e., the extent to which the websites were appealing to the senses [46]. Therefore, a new cohort of 26 students was exposed to three screenshots of the website (text only vs. text with photograph vs. text with drawing) and asked to rate which of the websites they perceived as most vivid and which visual cue they perceived as most realistic. As expected, the website with the photograph was considered to be most vivid by 17 (65.4\%) participants, which was significantly more than the $9(34.6 \%)$ and $0(0 \%)$ participants who considered the website with the drawing $(\mathrm{p}<0.05)$ and the website with text only $(\mathrm{p}<0.001)$, respectively, as more vivid. Additionally, in line with expectations, 21 (80.8\%) participants found the photograph more realistic than the drawing $(\mathrm{p}<0.001)$.

Fig. 2 shows the screenshot with text only (original website), Fig. 3 shows the screenshot with the labelled photograph (hereafter, 'photograph'), and Fig. 4 shows the screenshot with the labelled drawing (hereafter, 'drawing') that were used as stimulus material.

\section{[FIGURE 2] [FIGURE 3] [FIGURE 4]}

\subsubsection{Pre-test language complexity}


Weert, J.C.M. van, Noort, G. van, Bol, N., Dijk, L. van, Tates, K., Jansen, J. Tailored information for cancer patients on the Internet: effects of visual cues and language complexity on

information recall and satisfaction. Patient Education and Counseling: 2011, 84(3), 368-37

As explained in Section 1, the original website text was perceived as complex and was used in the complex language conditions. For the non-complex language conditions, two different versions of the original website text were created that used less complex language. In both non-complex versions, medical jargon was replaced by explanations in informal language, but the two versions differed in terms of sentence construction. Thirty-five students each randomly received one of the three versions and were asked to complete the aforementioned five-item scale to assess the extent to which the text facilitated understanding. The complexlanguage version appeared to be significantly more difficult to understand $(\mathrm{M}=4.48$, $\mathrm{SD}=0.86)$ than the first non-complex language version $(\mathrm{M}=5.55, \mathrm{SD}=0.89, \mathrm{p}<0.01)$ but was not significantly less understandable than the second version $(\mathrm{M}=5.27, \mathrm{SD}=0.58$, $\mathrm{p}>0.05$ ). We therefore chose the first non-complex language version as the stimulus material.

\subsection{Measures}

\subsubsection{Background characteristics}

The background questionnaire was administered first and contained socio-demographic items that inquired about age, gender, education and living situation. Next, other factors that might influence recall and/or satisfaction scores were measured, including online surfing behaviour, cancer history (self and important others) and knowledge about the lungs and lung cancer (treatment).

\subsubsection{Information recall}

In addition, information recall was measured using an adapted version of the "Netherlands Patient Information Recall Questionnaire' (NPIRQ [74]) that consisted of a set of five openended questions. Respondents typed in their answers into the online questionnaire. The questionnaire was based on the information displayed on the website and contained questions about the lungs (questions 1 and 4) and lung cancer treatment (questions 2, 3 and 5). The answers to these questions were judged by independent coders who were blind to the participants' assigned condition. The coders used a marking system that was developed before the questionnaire was administered. Questions 1,2 and 5 could score a maximum of two points, and questions 3 and 4 could score a maximum of one point. For each participant, a total recall score was calculated with a range of $0-8$.

Interrater reliability was calculated for recall scores on half $(n=101)$ of the questionnaires and appeared to be good, with a mean Cohen's Kappa of 0.93 (range 0.67-1.00) [75].

\subsubsection{Time spent on the website}

The time participants spent on the website during the first period was measured as the time between the website's appearance on the screen and the participant's click of the 'next' button to move to the recall measurement.

\subsubsection{Satisfaction}

Next, satisfaction with the website was measured using seven statements that could be rated by the participants on a seven-point Likert scale (ranging from $1=$ strongly disagree to $7=$ strongly agree). Factor analysis using varimax rotation confirmed two satisfaction subscales with an explained variance of $70.6 \%$, i.e., 'satisfaction with comprehensibility' (three items, $\alpha=0.78$ ) and 'satisfaction with attractiveness' (four items, $\alpha=0.84$ ). The 'comprehensibility' subscale included items about the clarity of the textual information on the website, e.g., 'the website is easy to read' and 'the language used on the website is easy to understand'. The 'attractiveness' subscale included items about the extent to which the participants liked the website and referred to imagery information, e.g., 'the website looks nice' and 'the website is well developed'. For both subscales, a total mean score was 
Weert, J.C.M. van, Noort, G. van, Bol, N., Dijk, L. van, Tates, K., Jansen, J. Tailored information for cancer patients on the Internet: effects of visual cues and language complexity on

information recall and satisfaction. Patient Education and Counseling: 2011, 84(3), 368-378

calculated with a range of 1-7. The items of the 'attractiveness' subscale were based on the subscales 'entertainment' and 'informativeness' of the 'attitude towards the site scale' [76] and [77] and the 'aesthetic effects' category of the 'leisure satisfaction scale' [78]. The items of the 'comprehensibility' subscale were based on the 'physiological effects' category of the 'leisure satisfaction scale' [78].

\subsubsection{Manipulation check}

Finally, to check whether the ease of understanding of the web content was successfully manipulated, participants were asked to rate the extent to which the website information facilitated understanding according to four questionnaire items with a seven-point semantic differential scale. The items pertained to perceived ease, clarity, complexity and ease of understanding of the information on the website $(\alpha=0.82)$.

\subsection{Analysis}

Descriptive statistics were obtained on the background characteristics of the participants, and differences in these variables between groups were examined using chi-statistics or ttests wherever such tests were appropriate. For the main analysis, three separate 2 (complex vs. non-complex language) $\times 3$ (text only vs. labelled photograph vs. labelled drawing) ANOVAs were conducted with satisfaction with comprehensibility, attractiveness and information recall as the dependent variables. To test whether visual cues affect older participants more than younger patients, three separate $2(<50$ years vs. $\geq 50$ years $) \times 2$ (no visual vs. visual) ANOVAs were conducted with satisfaction with comprehensibility, attractiveness and information recall as the dependent variables. Because the latter analyses aimed to examine the added value of a visual in general, we did not make a distinction between a photograph and drawing, i.e., the condition for a 'visual' website was the presence of a photograph or drawing. All analyses were conducted using SPSS 16.

\section{RESULTS}

\subsection{Participants}

Table 1 shows the background characteristics of the participants. The majority of the participants was female, with a mean age of 39 years, and almost half had completed a highlevel education.

\section{[TABLE 1]}

There were no significant differences in the conditions of age, gender, education, living situation, online surfing behaviour, cancer experience and medical knowledge about the lungs and lung cancer (treatment) among the participants. There were also no differences in the condition of mean time spent on the website $(F(1,193)=1.03)$, which indicates that the amount of time spent on the website was equally distributed across conditions. Therefore, it was not necessary to control for covariates in further analyses.

\subsection{Manipulation check}

The analysis of variance showed that, as intended, the information on the websites with non-complex language was perceived as easier to understand than the information on the websites with complex language $\left(\mathrm{M}_{\text {complex }}=19.05, \mathrm{SD}=0.43 \mathrm{vs}\right.$. $\mathrm{M}_{\text {non-complex }}=21.05$, $\left.\mathrm{SD}=0.43 ; \mathrm{F}(1,198)=10.43, \mathrm{p}<0.001, \eta^{2}=0.05\right)$. Furthermore, the information on the websites with visual cues (photograph or drawing) was also assessed as easier to understand than the information on the websites without visual cues $\left(\mathrm{M}_{\text {text only }}=18.88, \mathrm{SD}=0.59\right.$ vs. $\left.\mathrm{M}_{\text {visuals }}=20.43, \mathrm{SD}=0.37 ; \mathrm{F}(1,198)=5.00, \mathrm{p}<0.05, \eta^{2}=0.03\right)$. Hence, the website content was successfully manipulated. 
Weert, J.C.M. van, Noort, G. van, Bol, N., Dijk, L. van, Tates, K., Jansen, J. Tailored information for cancer patients on the Internet: effects of visual cues and language complexity on information recall and satisfaction. Patient Education and Counseling: 2011, 84(3), 368-37

\subsection{Effects of language complexity and visual cues on information recall and satisfaction}

\subsubsection{Information recall}

As shown in Table 2, recall scores were higher in the non-complex language conditions than in the complex language conditions $\left(F(1,198)=13.93, \eta^{2}=0.07\right)$. Furthermore, recall scores were marginally significantly higher among participants exposed to a website with a photograph than among participants exposed to a website with text only $(\mathrm{F}(1,131)=3.59$, $\left.\eta^{2}=0.03\right)$. However, there was no significant difference between participants exposed to a website with a drawing and those exposed to a website with text only $(F(1,123)=1.43$, $\eta^{2}=0.01$ ). Although recall scores were higher among participants who viewed the website with a photograph than with a drawing, the difference was not significant. Fig. 5 shows the main effect of language complexity on information recall, and Fig. 6 shows the main effect of the use of visual cues. No interaction effects were found.

\section{[TABLE 2] [FIGURE 6]}

Fig. 7 shows the average recall score for all six experimental conditions. The use of noncomplex language combined with a photograph resulted in the highest recall score $(\mathrm{M}=3.99, \mathrm{SD}=2.17)$, and the combination of complex language with no visual cues resulted in the lowest recall score $(\mathrm{M}=2.02, \mathrm{SD}=1.52)$. The figure shows that all noncomplex language conditions resulted in higher recall scores than the complex language conditions, although this difference was not always significant. Recall scores in the noncomplex language/photograph condition were significantly higher than those in the complex language/no visuals condition (Mean diff. $=-1.94, \mathrm{SE}=0.78, \mathrm{p}<0.05$ ) and the complex language/drawing condition (Mean diff. $=-2.00, \mathrm{SE}=0.68, \mathrm{p}<0.05$ ) and were marginally significantly higher than those in the complex language/photograph condition (Mean diff. $=-1.84, \mathrm{SE}=0.68, \mathrm{p}<0.10)$. Other differences between conditions were not significant.

\section{[FIGURE 7]}

\subsubsection{Satisfaction with comprehensibility}

A main effect of a photograph and a drawing, as compared to text only, on satisfaction with comprehensibility was found (Table 2). Participants were more satisfied with the comprehensibility of websites that included a photograph than websites with text only ( $\mathrm{F}(1$, $131)=4.47, \eta 2=0.06)$. This effect was qualified by the interaction effect between language complexity and the use of a photograph $(F(1,128)=4.47, p<0.05, \eta 2=0.03)$. Simple effect analysis revealed that the effect of a photograph was significant for participants who were exposed to complex language $(\mathrm{F}(1,128)=12.79, \mathrm{p}<0.001, \eta 2=0.09)$ but not for participants who were exposed to non-complex language $(\mathrm{F}(1,128)<1)$. This means that a photograph adds value especially when complex language is used. Furthermore, satisfaction with the comprehensibility of websites that used a drawing was higher than with a website that had no visual cues $(\mathrm{F}(1,123)=7.18, \eta 2=0.06)$. Although there was no significant interaction effect between language complexity and the use of a drawing (as compared to text only), simple effect analysis showed a significant effect of a drawing for participants who were exposed to complex language $\left(F(1,121)=7.57, \mathrm{p}<0.01, \eta^{2}=0.06\right)$ but not for those who were exposed to non-complex language $(F(1,121)=1.15)$. There were no differences in satisfaction with comprehensibility between exposure to a photograph and exposure to a drawing.

No main effect of language complexity on satisfaction with comprehensibility was found $\left(\mathrm{F}(1,198)=2.05, \eta^{2}=0.01\right)$. 
Weert, J.C.M. van, Noort, G. van, Bol, N., Dijk, L. van, Tates, K., Jansen, J. Tailored information for cancer patients on the Internet: effects of visual cues and language complexity on

information recall and satisfaction. Patient Education and Counseling: 2011, 84(3), 368-37

\subsubsection{Satisfaction with attractiveness}

There was no main effect of the photograph $\left(F(1,131)=2.40, \eta^{2}=0.02\right)$ on satisfaction with attractiveness (Table 2). A marginally significant main effect was found between participants who were exposed to a website with a drawing and those who were exposed to a website with text only $\left(F(1,123)=2.87, \eta^{2}=0.02\right)$, which indicates that a website with a drawing increases perceived attractiveness as compared to text only. No differences were found in satisfaction with attractiveness between exposure to a photograph and exposure to a drawing. As expected, there was also no main effect of language complexity on satisfaction with attractiveness $(F(1,198)<1)$, and no interaction effects were found.

\subsubsection{Age effects}

Results showed no main effect of age on satisfaction with comprehensibility $(F(1,196)<1$, n.s.). However, an interaction effect on satisfaction with comprehensibility was found between age and the use of a visual cue $\left(F(1,196)=4.18, p<0.05, \eta^{2}=0.02\right)$. Simple effect analysis revealed that the effect of adding a visual cue to a website was significant for participants aged 50 years or older $\left(F(1,196)=11.98, \eta^{2}=0.06\right)$ but not for those younger than 50 years old $\left(F(1,196)=1.13, \eta^{2}=0.01\right)$. Fig. 8 and Table 3 depict this effect.

\section{[FIGURE 8] [TABLE 3]}

Furthermore, a main effect of age on satisfaction with attractiveness was found. Older participants ( $\geq 50$ years) generally judged the website to be more attractive than younger participants did $\left(\mathrm{M}_{\text {older }}=5.16, \mathrm{SD}=1.11\right.$ vs. $\left.\mathrm{M}_{\text {younger }}=4.72, \mathrm{SD}=0.97 ; \mathrm{p}<0.05\right)$. Although there was no interaction effect between age and the use of visuals $(F(1,196)=1.83$, $\left.\eta^{2}=0.01\right)$, simple effect analysis showed that the effect of adding a visual cue to a website was significant for older participants $\left(F(1,196)=4.93, \eta^{2}=0.03\right)$ but not for younger ones $\left(\mathrm{F}(1,196)<1, \eta^{2}<0.01\right)$. Hence, the attractiveness of a website with text only or a website with a visual cue was considered to be similar by younger people. However, older adults perceived a website with a visual cue to be significantly more attractive than a website with text only (see Fig. 9 and Table 3).

\section{[FIGURE 9]}

\section{DISCUSSION AND CONCLUSION}

\subsection{Discussion}

The results of this study indicate that the use of visual cues is especially important to increase satisfaction with comprehensibility, while the use of non-complex language seems to be more decisive for information recall. Although our literature review did not clearly indicate that visual cues should add value in the complex language conditions (vs. noncomplex language conditions), this idea intuitively makes sense. If people do not understand the text because the language is too complex, they may have an increased need for additional visual information to understand the information. Previous work has suggested that a visual cue may aid comprehension when people have difficulty understanding the text and aid information recall when people understand the text but find the information difficult to recall [42]. The results of this study indicate that satisfaction with comprehensibility may be a prerequisite for understanding the information, but this might not be sufficient to remember and reproduce the information. Apparently, clear and non-complex language is still needed for appropriate recall of the information. Because the scope of potential interactions among text, visual cues and learning processes seems to be broad [42], more research in health education is needed to understand this complex relationship. 
Weert, J.C.M. van, Noort, G. van, Bol, N., Dijk, L. van, Tates, K., Jansen, J. Tailored information for cancer patients on the Internet: effects of visual cues and language complexity on

information recall and satisfaction. Patient Education and Counseling: 2011, 84(3), 368-378

Our results show that satisfaction scores increase more among older ( $\geq 50$ years) than younger ( $<50$ years) adults when a visual cue is added. This supports the aforementioned idea that visual cues attract more attention from older adults than from younger adults and evoke positive feelings [65]. The idea that older people might benefit more than younger ones from the use of visual cues can be further explained by older adults' lower health literacy skills [68] and [69]. Older people exhibit a lower reading ability than younger people and are often considered poor readers. Several researchers have predicted that visual cues would help poor readers more than good readers [42]. However, recent research also indicates that older adults might not benefit from visual cues because visual cues can be difficult to integrate with text [68]. Although our results support the idea that the use of visual cues is more significant for older than for younger people, more research is needed in this area.

Contrary to our expectations, there were no differences in information recall between younger and older participants. Post hoc analysis demonstrated that older participants spent almost 1 min longer visiting the website $(M \geq 50=2.7 ; S D=3.7)$ than younger participants $(\mathrm{M}<50=1.8 ; \mathrm{SD}=4.0)$. Although the data do not provide an explanation for this difference, previous experimental research has reported that older people spent more time reading instructions [80], reading illustration-related phrases, fixating on illustrations [68] and executing tasks [80]. In addition, Morrow et al. [61] found that giving older participants extra study time improved their recall of information (Experiment 1), but that older adults' memories were not improved when study time was restricted (Experiment 2). The time that participants could spend on the website before completing the recall questionnaire was unrestricted in the current study, which might explain why the recall scores did not differ between age groups.

The effects of the use of visual cues on satisfaction might be explained by vividness. A pretest of the stimulus materials clearly demonstrated that the websites that included either a photograph or a drawing were perceived to be more vivid than the text-only website. This result is in line with prior studies conducted in the field of online marketing communication, which have shown that websites that provided virtual tours [53] or animations [79] were evaluated more positively and that moving pictures on a website enhanced memory retention scores [59]. The current study only applied still visual cues that complemented the textual health information. Therefore, future research should investigate whether moving images, such as an instructional video about a surgery, further enhance the quality of health websites. We predicted that a photograph would give better results than a drawing due to the higher vividness of a photograph, and the pre-test indeed showed that the website with the photograph was perceived as more vivid than the website with the drawing. However, the recall scores of the participants who were exposed to a website with a photograph $(\mathrm{M}=3.31)$ were not significantly higher than the recall scores of participants who viewed a website with a drawing $(\mathrm{M}=3.07)$, and the scores on satisfaction with comprehensibility $(\mathrm{M}=5.71 \mathrm{vs.}$ $5.63)$ and satisfaction with attractiveness $(\mathrm{M}=4.97 \mathrm{vs.} 4.94)$ were largely comparable. This indicates that vividness might explain the effectiveness of the use of visual cues in general but only partly explains the effectiveness of a photograph as compared to a drawing (H4 and H5).

\subsubsection{Limitations}

The first limitation of this experiment is the external validity of the results. Because the results were found in an experimental setting, the results cannot automatically be generalised to real-world settings, particularly because no cancer patients were included in this study. Cancer patients might evaluate the information presented by a tailored website differently than others. Cancer patients might be more involved and motivated to process the information than the participants of the current study, which could lead to more elaborate processing if information processing theory holds. However, being diagnosed with cancer is 
Weert, J.C.M. van, Noort, G. van, Bol, N., Dijk, L. van, Tates, K., Jansen, J. Tailored information for cancer patients on the Internet: effects of visual cues and language complexity on

information recall and satisfaction. Patient Education and Counseling: 2011, 84(3), 368-372

a stressful event for most patients, and stress and emotions might decrease their cognitive processing ability. Moreover, the mean age of lung cancer patients treated in the NCI-AVL is higher than the mean age of the participants in the current study. Consequently, education and health literacy are probably lower in real lung cancer patients than in our study population. Although this makes it more important to strive for easy-to-read information, it is recommended that the study should be replicated among cancer patients.

In addition, the satisfaction with comprehensibility measurement was not an absolute measurement of the readability of the text but rather a reflection of the participants' opinions of the comprehensibility. It is recommended that a textual analysis should be conducted in future research, for instance, by using functional analysis or a readability instrument [81] to compare perceived satisfaction with objective readability. It is possible that earlier studies did not find an interaction effect between language complexity and the use of visual cues because those studies examined an absolute level of complexity (for instance, low vs. medium complexity) that differed from the level used in the current study (for instance, medium vs. high complexity).

\subsection{Conclusion}

An experimental study examined whether lower levels of language complexity and the use of visual cues, i.e., a labelled photograph or a labelled drawing, enhance the patients' satisfaction with the information on a tailored website and increase information recall. As expected, language complexity did not affect satisfaction but had a significant effect on information recall (H1). Participants who were exposed to one of the non-complex language conditions showed significantly higher recall scores than those who read complex language. The use of a photograph resulted in marginally significant higher recall scores than the use of text only (H2), and participants who were exposed to the non-complex language/photograph condition showed the highest recall score (H7). The results also show that participants were more satisfied with the comprehensibility of the websites that used a visual cue (H3). In addition, we found that language complexity and the use of a photograph had a significant interaction effect on satisfaction with comprehensibility, which indicates that especially complex language can benefit from the inclusion of a photograph.

Finally, we examined age effects. The results showed an interaction effect between age and satisfaction with comprehensibility. Older adults ( $\geq 50$ years) who were exposed to a website with a visual cue were significantly more satisfied with comprehensibility than older adults who were exposed to a website with text only $(<50$ years) $(\mathrm{H} 8)$. The results indicate that adding a visual cue is more important for older adults than for younger ones, although the predicted differences between younger and older adults in information recall (H9) were not found.

\subsection{Practice implications}

Tailored messages are a promising medium to communicate information to patients, and personalised websites may help patients find relevant health information. The findings of this study support further improvement of this type of tailored intervention. First, the findings clearly demonstrate that adjusting the level of language complexity greatly improves the website visitor's level of processing because information recall was higher in the noncomplex language conditions. Therefore, online health information websites should be tailored not only to the informational needs of the patients but also to their reading level. Second, the findings demonstrate that the use of visual cues increases satisfaction with comprehensibility and improves older adults' satisfaction with attractiveness. Therefore, designers of health information websites should use visual cues that support key informational content. There is general agreement in the literature that visuals without irrelevant details should be chosen [24] and [52], but it is difficult to determine which information is 'irrelevant'. This indicates that visual cues to be used in health education should always be field-tested with the intended audience before being deployed [40]. Moreover, the relationship between the text and the visual cue appears critical, especially 
Weert, J.C.M. van, Noort, G. van, Bol, N., Dijk, L. van, Tates, K., Jansen, J. Tailored information for cancer patients on the Internet: effects of visual cues and language complexity on

information recall and satisfaction. Patient Education and Counseling: 2011, 84(3), 368-378

when the aim is to improve information recall. When text is accompanied by complementary illustrations, there is an information overlap. Visual cues are supposed to facilitate the text that is shown in the visual cue, but not the text that is not illustrated [42]. This means that health website designers should field-test which information is most important and/or most difficult to understand before deciding which parts of the text will be illustrated.

\section{ROLE OF FUNDING}

This study was funded by the Amsterdam School of Communication Research ASCoR from the University of Amsterdam, Amsterdam, The Netherlands. ASCoR management was not involved in study design; data collection, analysis and interpretation of data; in the writing of the report; and in the decision to submit the paper for publication.

\section{ACKNOWLEDGEMENTS}

The authors thank the Netherlands Cancer Institute-Antoni van Leeuwenhoek Hospital, in particular Carola Koopman, for the nice cooperation and permission to use their personalized website for lung cancer patients. Furthermore, we thank the students Communication Science of the University of Amsterdam who participated in this study for their collaboration in data collection.

\section{REFERENCES}

[1] Internet World Stats. Internet usage statistics: World Internet users and population stats. Downloaded on February 10, 2010, from http://www.Inter-networldstats.com/stats.htm.

[2] J. Fogel, Internet use for cancer information among racial/ethnic populations and low literacy groups, Cancer Control 10 (2003), pp. 45-51.

[3] J. Fogel, S.M. Albert, F. Schnabel, B.A. Ditkoff and A.I. Neugut, Racial/ethnic differences and potential psychological benefits in use of the Internet by women with breast cancer, Psycho-Oncology 12 (2003), pp. 107-117.

[4] T.F. Hack, L.F. Degner and P.A. Parker, The communication goals and needs of cancer patients: a review, Psycho-Oncology 14 (2005), pp. 831-845.

[5] J.M. Morahan-Martin, How Internet users find, evaluate, and use online health information: a cross-cultural review, Cyberpsychol Behav 7 (2004), pp. 497-510.

[6] R.E. Rice and J.E. Katz, Internet use in physician practice and patient interaction. In: M. Murero and R.E. Rice, Editors, The internet and health care: theory, research and practice, Lawrence Erlbaum Associates, Mahwah, NJ (2006), pp. 149-176.

[7] G. Eysenbach, The impact of the internet on cancer outcomes, CA Cancer J Clin 53 (2003), pp. 356-371.

[8] Kessels, Patients' memory for medical information, J R Soc Med 96 (2003), pp. 219-222

[9] C. Cameron, Patient compliance: recognition of factors involved and suggestions for promoting compliance with therapeutic regimens, J Adv Nurs 24 (1996), pp. 244-250.

[10] S. Galloway, J. Graydon, D. Harrison, B. Evans-Boyden, S. Palmer-Wickham and S. Burlein-Hall et al., Informational needs of women with a recent diagnosis of breast cancer: development and initial testing of a tool, J Adv Nurs 25 (1997), pp. 1175-1183.

[11] J. Mossman, M. Boudioni and M.L. Slevin, Cancer information: a cost-effective intervention, Eur J Cancer 35 (1999), pp. 1587-1591.

[12] J.L. Monahan, Thinking positively: using positive affect when designing health messages. In: E.W. Maibach and R.L. Parrot, Editors, Designing health messages: approaches from communication theory and public health practice, Sage, Thousand Oaks, CA (1995), pp. 81-98.

[13] M. Avis, R. Elkan, S. Patel, B. Walker, N. Ankti and C. Bell, Ethnicity and participation in cancer self-help groups, Psycho-Oncology 17 (2008), pp. 940-947.

[14] H. Kakai, G. Maskarinec, D.M. Shumay, Y. Tatsumura and K. Tasaki, Ethnic differences in choices of health information by cancer patients using complementary and alternative medicine: an exploratory study with correspondence analysis, Soc Sci Med 56 (2003), pp. 851-862. 
Weert, J.C.M. van, Noort, G. van, Bol, N., Dijk, L. van, Tates, K., Jansen, J. Tailored information for cancer patients on the Internet: effects of visual cues and language complexity on

information recall and satisfaction. Patient Education and Counseling: 2011, 84(3), 368-378

[15] M.L. Lustria, J. Cortese, S.M. Noar and R.L. Glueckauf, Computer-tailored health interventions delivered over the web: review and analysis of key components, Patient Educ Couns 74 (2009), pp. 156-173.

[16] B.K. Rimer and M.W. Kreuter, Advancing tailored health communication: a persuasion and message effects perspective, J Commun 6 (2006), pp. S184-S201.

[17] J. Brug, M. Campbell and P. Van Assema, The application and impact of computergenerated personalized nutrition education: a review of the literature, Patient Educ Couns 36 (1999), pp. 145-156.

[18] W. Kroeze, A. Werkman and J. Brug, A systematic review of randomized trials on the effectiveness of computer-tailored education on physical activity and dietary behaviors, Ann Behav Med 31 (2006), pp. 205-223.

[19] S.M. Noar, C.N. Benac and M.S. Harris, Does tailoring matter? Meta-analytic review of tailored print health behavior change interventions, Psychol Bull 133 (2007), pp. 673-693.

[20] V.J. Strecher, Computer-tailored smoking cessation materials: a review and discussion, Patient Educ Couns 36 (1999), pp. 107-117.

[21] N. Van der Meulen, J. Jansen, A.M. Van Dulmen, J.M. Bensing and J.C.M. Van Weert, Interventions to improve recall of medical information in cancer patients: a systematic review of the literature, Psycho-Oncology 17 (2008), pp. 857-868.

[22] S.T. Walters, J.A. Wright and R. Shegog, A review of computer and Internet-based interventions for smoking behavior, Addict Behav 31 (2006), pp. 264-277.

[23] G.K. Berland, M.N. Elliott, L.S. Morales, J.I. Algazy, R.L. Kravitz and M.S. Broder et al., Health information on the Internet: accessibility, quality, and readability in English and Spanish, J Amer Med Assoc 285 (2001), pp. 2612-2621.

[24] C. Doak, L.G. Doak, G.H. Friedell and C.D. Meade, Improving comprehension for cancer patients with low literacy skills: strategies for clinicians, CA Cancer J Clin 48 (1998), pp. 151-162.

[25] M.A. Graber, C.M. Roller and B. Kaeble, Readability levels of patient education material on the World Wide Web, J Fam Pract 48 (1999), pp. 58-61.

[26] W. Tuil, IVF and Internet. Evaluation of an interactive personal health record for IVF patients, Radboud University, Nijmegen (2008).

[27] J.R. Levin, G.J. Anglin and R.N. Carney, On empirically validating functions of pictures in prose. In: D.M. Willows and H.A. Houghton, Editors, The psychology of illustration: vol.

1. Basic research, Springer-Verlag, New York (1987), pp. 51-85.

[28] R.E. Petty and J.T. Cacioppo, Attitudes and persuasion: classic and contemporary approaches, William C. Brown, Dubuque, IA (1981).

[29] R.E. Petty and J.T. Cacioppo, Communication and persuasion: central and peripheral routes to attitude change, Springer-Verlag, New York (1986).

[30] R. Batra and M.L. Ray, Situational effects of advertising repetition: the moderating influence of motivation ability, and opportunity to respond, J Consum Res 12 (1986), pp. 432-445.

[31] J.C. Andrews, Motivation, ability, and opportunity to process information: conceptual and experimental manipulation issues. In: M.J. Houston, Editor, Advances in consumer research vol. 15, Association for Consumer Research, Provo, UT (1988), pp. 219-225.

[32] P. Austin, R. Matlack, K. Dunn, C. Kesler and C. Brown, Discharge instructions: do illustrations help our patients understand them?, Ann Emerg Med 25 (1995), pp. 317-320.

[33] G.C. Baker, D. Newton and P. Bergstresser, Increased readability improves the comprehension of written information for patients with skin disease, $\mathrm{J}$ Am Acad Dermatol 19 (1988), pp. 1135-1141.

[34] T. Davis, M. Crouch, S. Wills, S. Miller and D. Abdehou, The gap between patient reading comprehension and the readability of patient education materials, J Fam Pract 31 (1990), pp. 533-538.

[35] T. Davis, J. Bocchini, D. Fredrickson, C. Arnold, J. Mayeux and P. Murphy et al., Parent comprehension of polio vaccine information pamphlets, Pediatrics 97 (1996), pp. 804-810.

[36] R. Jolly, J. Scott and S. Sanford, Simplification of emergency departments discharge instructions improves patient comprehension, Ann Emerg Med 26 (1995), pp. 443-446.

[37] C. Meade, J. Byrd and M. Lee, Improving patient comprehension of literature on smoking, Am J Public Health 79 (1989), pp. 1411-1412. 
Weert, J.C.M. van, Noort, G. van, Bol, N., Dijk, L. van, Tates, K., Jansen, J. Tailored information for cancer patients on the Internet: effects of visual cues and language complexity on

information recall and satisfaction. Patient Education and Counseling: 2011, 84(3), 368-378

[38] R. Michielutte, J. Bahnson, M. Dignan and E. Schroeder, The use of illustrations and narrative text style to improve readability of a health education brochure, J Cancer Educ 7 (1992), pp. 251-260.

[39] J. Root and S. Stableford, Easy-to-read consumer communications: a missing link in Medicaid managed care, J Health Polit 24 (1999), pp. 1-26.

[40] P.S. Houts, C.C. Doak, L.G. Doak and M.J. Loscalzo, The role of pictures in improving health communication: a review of research attention, comprehension, recall, and adherence, Patient Educ Couns 61 (2006), pp. 173-190.

[41] G. Leroy, S. Helmreich and J.R. Cowie, The influence of text characteristics on perceived and actual difficulty of health information, Int J Med Inf 79 (2010), pp. 438-449.

[42] W.H. Levie and R. Lentz, Effect of tect illustrations: a review of research, Educ Commun Technol J 30 (1982), pp. 195-232.

[43] A. Paivio, Mental representations: a dual-coding approach, Oxford University Press, New York (1986).

[44] R.E. Mayer and R. Moreno, Aids to computer-based multimedia learning, Eur Res Int 12 (2002), pp. 107-119.

[45] D.E. Rosen and E. Purinton, Website design: viewing the web as a cognitive landscape, J Bus Res 57 (2004), pp. 787-794.

[46] J. Steuer, Defining virtual reality: dimensions deter-mining telepresence, J Commun 42 (1992), pp. 73-93.

[47] R. Nisbett and L. Ross, Human inference: strategies and shortcomings of social judgment, Prentice-Hall, Englewood Cliffs, NJ (1980).

[48] Z. Jiang and I. Benbasat, Investigating the influence of the functional mechanisms of online product presentations, Inform Syst Res 18 (2007), pp. 454-470.

[49] R. Dowse and M. Ehlers, Medicine labels incorporating pictograms: do they influence understanding and adherence?, Patient Educ Couns 58 (2006), pp. 63-70.

[50] M.G. Katz, S. Kripalani and B.D. Weiss, Use of pictorial aids in medication instructions: a review of the literature, Am J Health-Syst Ph 63 (2006), pp. 2391-2397.

[51] M. Kools, M.W.J. Van de Wiel, R.A.C. Ruiter and G. Kok, Pictures and text in instructions for medical devices: effects on recall and actual performance, Patient Educ Couns 64 (2006), pp. 104-111.

[52] J. Choi and S. Bakken, Web-based education for low-literate parents in Neonatal Intensive Care Unit: development of a website and heuristic evaluation and usability testing, Int J Med Inform 79 (2010), pp. 565-575.

[53] S.J. McMillan, J.S. Hwang and G. Lee, Effects of structural and perceptual factors on attitudes toward the website, J Advertising Res 43 (2003), pp. 400-409.

[54] Y.K. Choi, G.R. Miracle and F. Biocca, The effects of anthropomorphic agents on advertising effectiveness and the mediating role of presence, $\mathrm{J}$ Interact Advertising 2 (2001).

[55] J.R. Coyle and E. Thorson, The effects of progressive levels of interactivity and vividness in web marketing sites, J Advertising 30 (2001), pp. 65-77.

[56] D. Filippatou and P.D. Pumfrey, Pictures, titles, reading accuracy and reading comprehension: a research review (1973-95), Educ Res 38 (1996), pp. 259-291.

[57] J.M. Moll, Doctor-patient communication in rheumatology: studies of visual and verbal perception using educational booklets and other graphic material, Ann Rheum Dis 45 (1986), pp. 198-209.

[58] J.E. Readance and D.W. Moore, A meta-analytic review of the effect of adjunct pictures on reading comprehension, Psychol Schools 18 (1981), pp. 218-224.

[59] W. Lee and I. Benbasat, Designing an electronic commerce interface: attention and product memory as elicited by web design, Electron Commer R A 2 (2003), pp. 240-253.

[60] M.T. Elliott and P.S. Speck, Factors that affect attitude towards a retail web site, J Marketing Theor Pract 13 (2005), pp. 40-51.

[61] D.G. Morrow, C.M. Hier, W.E. Menard and V.O. Leirer, Icons improve older and younger adults' comprehension of medication information, J Geront: Psychol Sci 53B (1998), pp. 240-254.

[62] In: M.J. Horner, L.A.G. Ries, M. Krapcho, N. Neyman, R. Aminou and N. Howlader et al., Editors, SEER cancer statistics review, 1975-2006, National Cancer Institute, 
Weert, J.C.M. van, Noort, G. van, Bol, N., Dijk, L. van, Tates, K., Jansen, J. Tailored information for cancer patients on the Internet: effects of visual cues and language complexity on

information recall and satisfaction. Patient Education and Counseling: 2011, 84(3), 368-378

Bethesda, MD (2009) http://seer.cancer.gov/csr/1975_2006/, based on November 2008 SEER data submission, posted to the SEER web site.

[63] L. Sparks and M.M. Turner, The impact of cognitive and emotive communication barriers on older adult message processing of cancer-related health information: new directions for research. In: L. Sparks, H.D. O'Hair and G.L. Kreps, Editors, Cancer, communication and aging, Hampton Press, Inc., New York (2008), pp. 17-47.

[64] T.M. Hess, Memory and aging in context, Psychol Bull 131 (2005), pp. 383-406.

[65] M. Mather and L.L. Carstensen, Aging and motivated cognition: the positivity effect in attention and memory, Trends Cogn Sci 9 (2005), pp. 496-502.

[66] A. Carstens, A. Maes and L. Gangla-Birir, Understanding visuals in HIV? AIDS education in South Africa: differences between literate and low-literate audiences, Afr J AIDS Res 5 (2006), pp. 1-12.

[67] R. Dowse and M. Ehlers, The influence of education on the interpretation of pharmaceutical pictograms for communicating medicine instructions, Int J Pharm Pract 11 (2003), pp. 11-18.

[68] C. Liu, S. Kemper and J. McDowd, The use of illustration to improve older adults' comprehension of health-related information: is it helpful?, Patient Educ Couns 76 (2009), pp. 283-288.

[69] J.A. Gazmararian, D.W. Baker, M.V. Williams, R.M. Parker, T.L. Scott and D.C. Green et al., Health literacy among medicare enrollees in a managed care organization, J Amer Med Assoc 281 (1999), pp. 545-551.

[70] B.A. Ally, J.D. Waring, E.H. Beth, J.D. McKeever, W.P. Milberg and A.E. Budson, Aging memory for pictures: using high-density event-related potentials to understand the effect of aging on the picture superiority effect, Neuropsychologia 46 (2008), pp. 679-689.

[71] A.M. Glenberg and W.E. Langston, Comprehension of illustrated text: pictures help to build mental models, J Mem Lang 31 (1992), pp. 129-151.

[72] J.H. Larkin and H.A. Simon, Why a diagram is (sometimes) worth ten thousand words, Cogn Sci 11 (1987), pp. 65-99.

[73] P.J. Danaher and G.W. Mullarkey, Factors affecting online advertising recall: a study of students, J Advertising Res 43 (2003), pp. 252-267.

[74] J. Jansen, J.C.M. Van Weert, N. Van der Meulen, S. Van Dulmen, T.H. Heeren and J.M. Bensing, Recall in older cancer patients: measuring memory for medical information, Gerontologist 48 (2008), pp. 149-157.

[75] D.G. Altman, Practical statistics for medical research, Chapman \& Hall, London (1991).

[76] Q. Chen and W.D. Wells, Attitude toward the site, J Advertising Res 39 (1999), pp. 2737.

[77] G. Van Noort, P. Kerkhof and B.M. Fennis, The persuasiveness of online safety cues: the impact of prevention focus compatibility of web content on consumers' risk perceptions, attitudes, and intentions, J Interact Mark 22 (2008), pp. 58-72.

[78] J.G. Beard and M.G. Ragheb, Measuring leisure satisfaction, J Leisure Res 12 (1980), pp. 20-33.

[79] A.A. Raney, L.M. Arpan and K. Pashupati, At the movies, on the web: an investigation of the effects of entertaining and interactive web content on site and brand evaluations, $\mathrm{J}$ Interact Mark 17 (2003), pp. 38-53.

[80] F. Van Horen, C. Jansen, L. Noordman and A. Maes, Manuals for the elderly: text characteristics that help or hinder older users, IEEE Int Prof Commun C Proc 2005 (2011), pp. 334-342.

[81] D.B. Friedman and L. Hoffman-Goetz, A systematic review of readability and comprehension instruments used for print and web-based cancer information, Health Educ Behav 33 (2006), pp. 352-373. 
Weert, J.C.M. van, Noort, G. van, Bol, N., Dijk, L. van, Tates, K., Jansen, J. Tailored information for cancer patients on the Internet: effects of visual cues and language complexity on information recall and satisfaction. Patient Education and Counseling: 2011, 84(3), 368-378

\section{TABLES AND FIGURES}

\section{Figure 1}

\begin{tabular}{l|llll} 
& \multicolumn{3}{|c}{ Visual cues } \\
& Text only & Photograph & Drawing \\
\hline & Condition 1 & Condition 2 & Condition 3 \\
$n=27$ & $n=40$ & $n=39$ \\
Condition 4 & Condition 5 & Condition 6 \\
$n=30$ & $n=35$ & $n=29$
\end{tabular}

Fig. 1. The 2 (complex vs. non-complex language) $\times 3$ (text only vs. labelled photograph vs. labelled drawing) factorial design $(N=200)$.

\section{Figure 2}

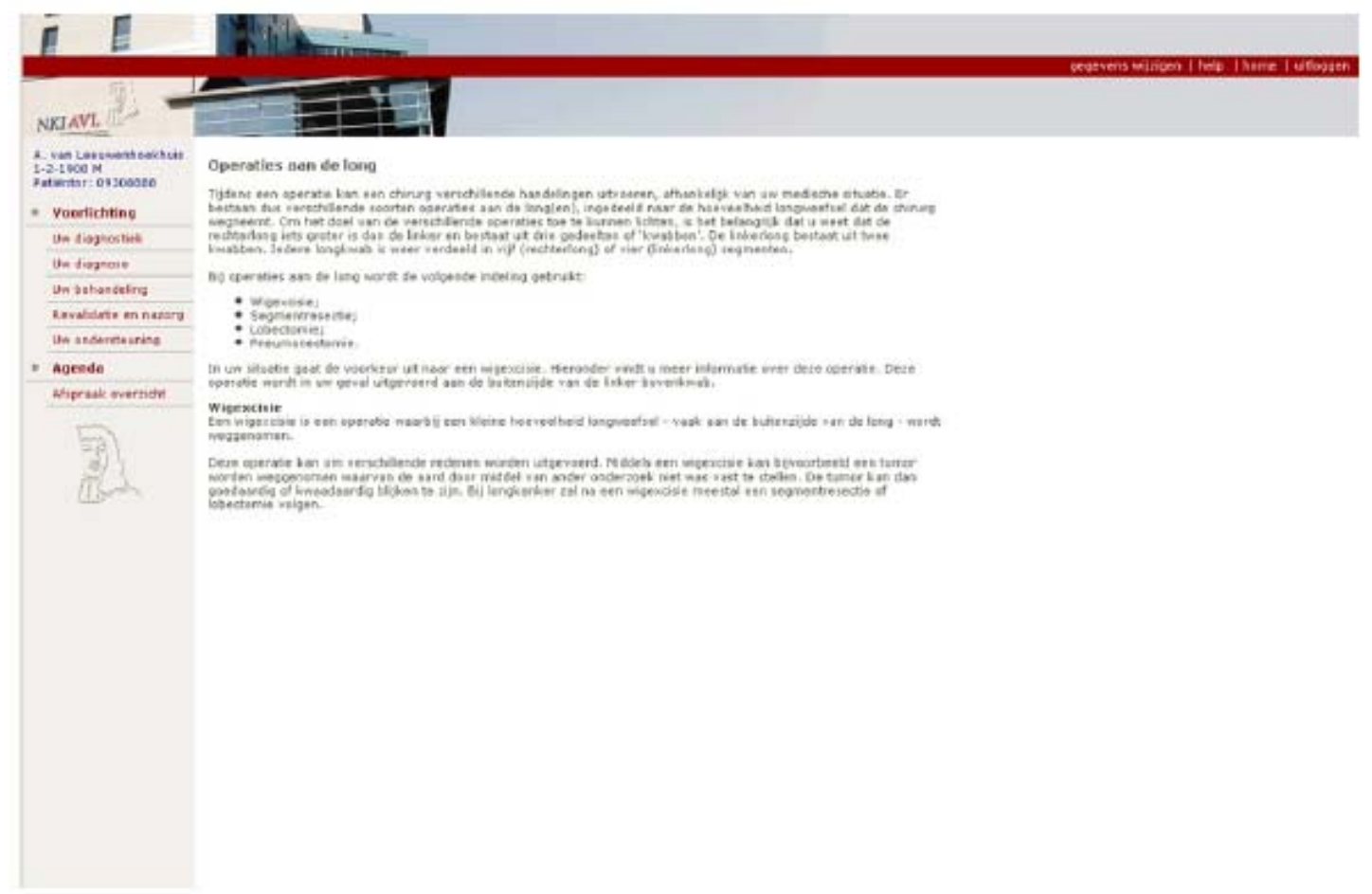

Fig. 2. Condition 1 (complex language - text only). 
Weert, J.C.M. van, Noort, G. van, Bol, N., Dijk, L. van, Tates, K., Jansen, J. Tailored information for cancer patients on the Internet: effects of visual cues and language complexity on information recall and satisfaction. Patient Education and Counseling: 2011, 84(3), 368-37

\section{Figure 3}

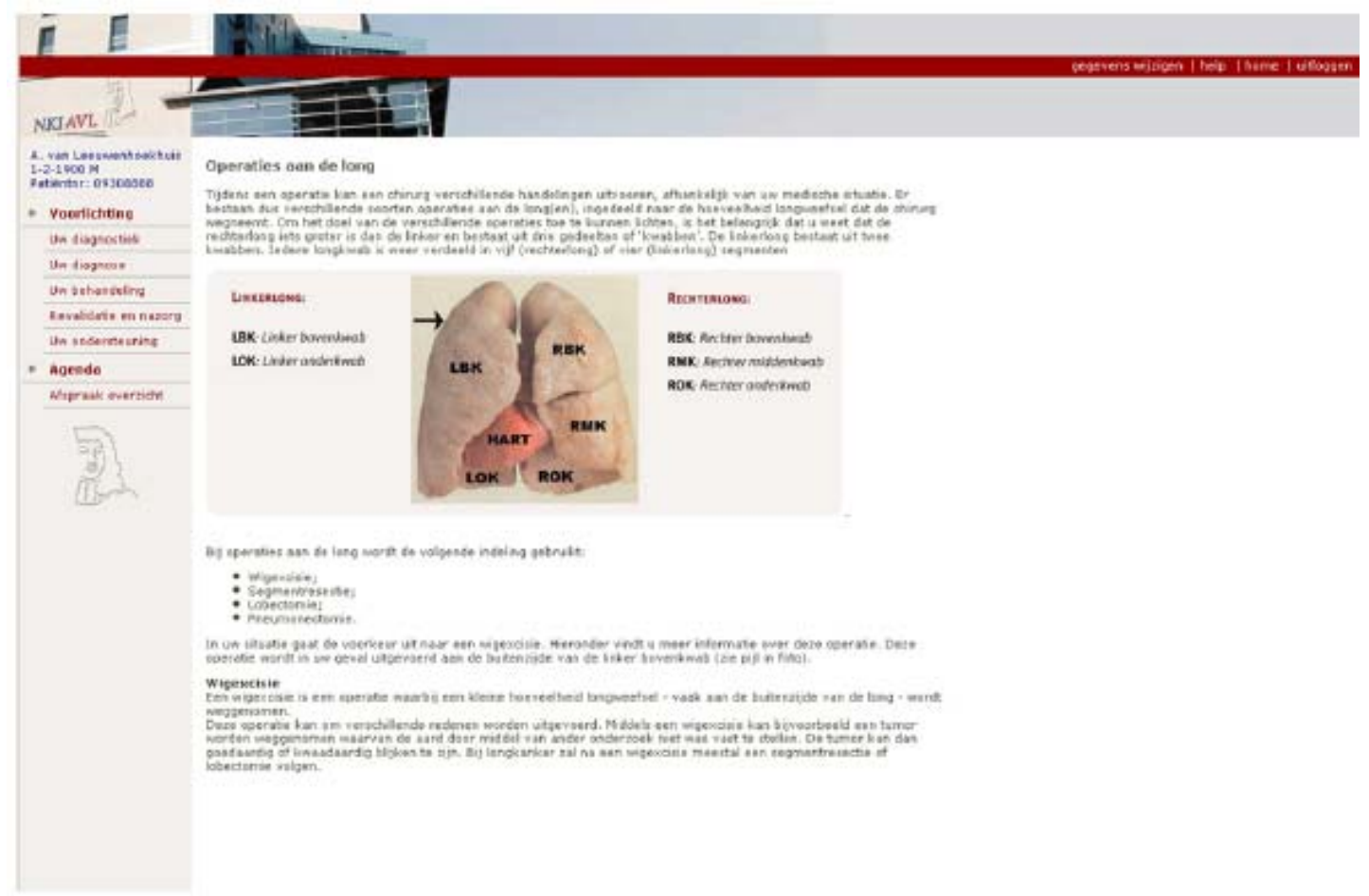

Fig. 3. Condition 2 (complex language - labelled photograph). 
Weert, J.C.M. van, Noort, G. van, Bol, N., Dijk, L. van, Tates, K., Jansen, J. Tailored information for cancer patients on the Internet: effects of visual cues and language complexity on information recall and satisfaction. Patient Education and Counseling: 2011, 84(3), 368-37

\section{Table 1}

Table 1

Characteristics of participants $(N=200)$.

\begin{tabular}{|c|c|c|}
\hline & $n$ & $\mathscr{\%}$ \\
\hline \multicolumn{3}{|l|}{ Gender } \\
\hline Male & 77 & 38.5 \\
\hline Female & 123 & 61.5 \\
\hline \multicolumn{3}{|l|}{ Age } \\
\hline$M(\mathrm{SD})$ & \multicolumn{2}{|c|}{$39.2(15.8)$} \\
\hline \multicolumn{3}{|l|}{ Educational level } \\
\hline Low & 35 & 17.5 \\
\hline Middle & 66 & 33.0 \\
\hline High & 99 & 49.5 \\
\hline \multicolumn{3}{|l|}{ Living arrangements } \\
\hline Alone & 31 & 15.5 \\
\hline With partner & 60 & 30.0 \\
\hline With partner and child(ren) & 54 & 27.0 \\
\hline With parents & 25 & 12.5 \\
\hline Other & 30 & 15.0 \\
\hline \multicolumn{3}{|l|}{ Student } \\
\hline Yes & 48 & 24.0 \\
\hline \multicolumn{3}{|l|}{ Internet usage (number of hours per week) } \\
\hline$<3 \mathrm{~h}$ & 69 & 34.5 \\
\hline $3-10 \mathrm{~h}$ & 102 & 51.0 \\
\hline$\geq 10 \mathrm{~h}$ & 29 & 14.5 \\
\hline \multicolumn{3}{|l|}{ Searching health information on the Internet } \\
\hline Never & 34 & 17.0 \\
\hline$<3$ times a year & 72 & 36.0 \\
\hline 3-11 times a year & 62 & 31.0 \\
\hline$\geq$ once a month & 32 & 16.0 \\
\hline \multicolumn{3}{|l|}{ Experience with cancer } \\
\hline Self being treated for cancer & 6 & 3.0 \\
\hline Someone close treated for cancer & 159 & 79.5 \\
\hline Someone close treated for lung cancer & 34 & 17.0 \\
\hline \multicolumn{3}{|l|}{ Perceived cancer lnowledge (scale $1-7)^{2}$} \\
\hline$M(\mathrm{SD})$ & 2.9( & \\
\hline Perceived lung cancer treatment knowledge (scale $1-7)^{2}$ & 1.8( & \\
\hline
\end{tabular}

Note: There were no significant differences between conditions in background characteristics.

a A higher score indicates more knowledge.

\section{Table 2}

Table 2

Main effects of language complexity and visual cues on satisfaction and information recall $(N=200)$.

\begin{tabular}{|c|c|c|c|c|c|c|}
\hline & \multicolumn{2}{|c|}{$\begin{array}{l}\text { Satisfaction with } \\
\text { comprehensibility }\end{array}$} & \multicolumn{2}{|c|}{$\begin{array}{l}\text { Satisfaction with } \\
\text { attractiveness }\end{array}$} & \multicolumn{2}{|c|}{ Recall of information } \\
\hline & M & SD & $M$ & SD & $M$ & SD \\
\hline \multicolumn{7}{|l|}{ Visual cues } \\
\hline Text only $(n=57)$ & $5.18^{2^{2 *} \cdot h^{* *}}$ & 1.05 & $4.67^{b, \pi}$ & 0.92 & $2.62^{2 \pi}$ & 2.11 \\
\hline Photograph $(n=75)$ & 5.72 & 1.10 & 4.97 & 1.19 & 3.31 & 2.18 \\
\hline Drawing $(n=68)$ & 5.65 & 1.09 & 4.94 & 0.93 & 3.07 & 2.16 \\
\hline \multicolumn{7}{|l|}{ Language complexity } \\
\hline Complex $(n=106)$ & 5.44 & 1.16 & 4.83 & 1.05 & $2.48^{c \cdots}$ & 1.85 \\
\hline Non-complex $(n=94)$ & 5.66 & 1.01 & 4.93 & 1.02 & 3.59 & 2.33 \\
\hline
\end{tabular}

Text only, website without visual cues; photograph, website with photograph; drawing, website with drawing.

*. $p<0.10$.

- $p<0.01$.

a Significant difference between text only and photograph

b Significant difference between text only and drawing.

Significant difference between complex and non-complex language. 
Weert, J.C.M. van, Noort, G. van, Bol, N., Dijk, L. van, Tates, K., Jansen, J. Tailored information for cancer patients on the Internet: effects of visual cues and language complexity on information recall and satisfaction. Patient Education and Counseling: 2011, 84(3), 368-37

\section{Figure 5}

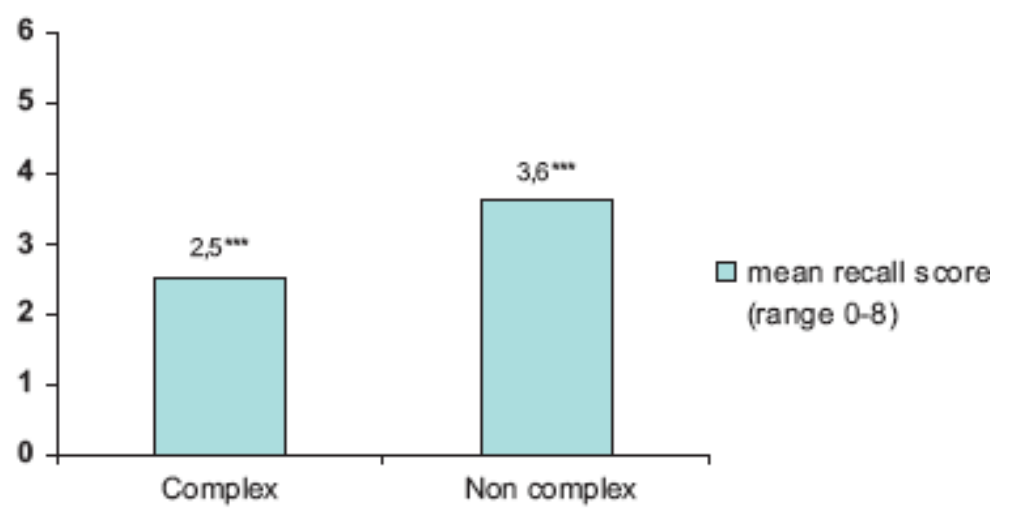

Fig. 5. Effect of language complexity on information recall (main effect).

\section{Figure 6}

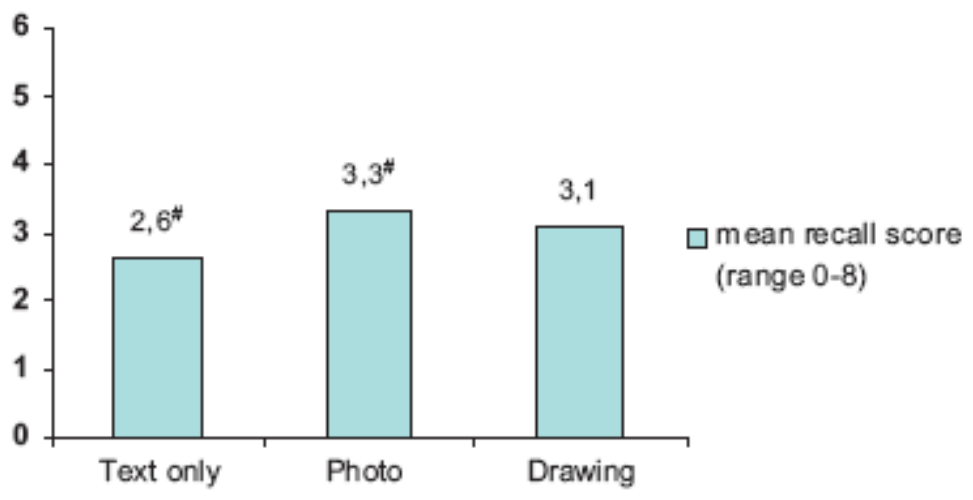

Fig. 6. Effect of visual cues (labelled photograph or labelled drawing) on recall (main effect).

\section{Figure 7}

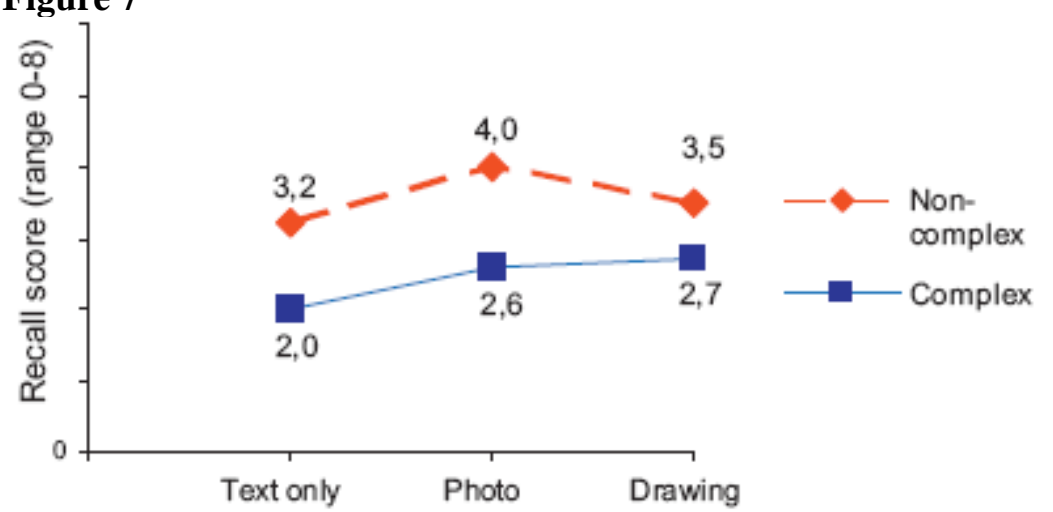

Fig. 7. Effect of language complexity and visual cues (labelled photograph or labelled drawing) on information recall.

Figure 8 
Weert, J.C.M. van, Noort, G. van, Bol, N., Dijk, L. van, Tates, K., Jansen, J. Tailored information for cancer patients on the Internet: effects of visual cues and language complexity on information recall and satisfaction. Patient Education and Counseling: 2011, 84(3), 368-37

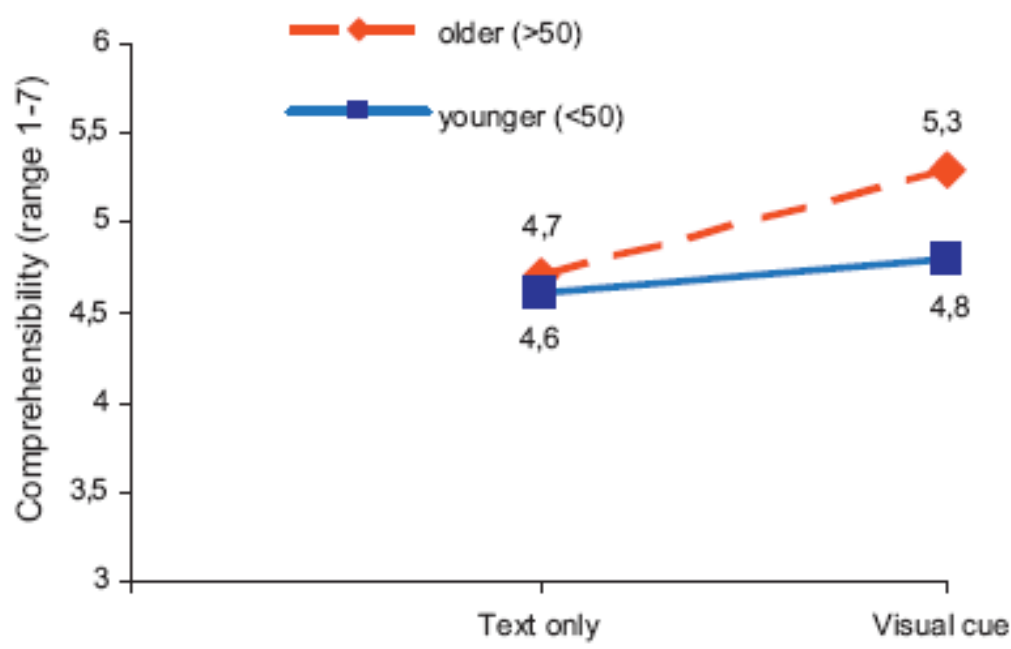

Fig. 8. Age-differences on satisfaction with comprehensibility.

\section{Figure 9}

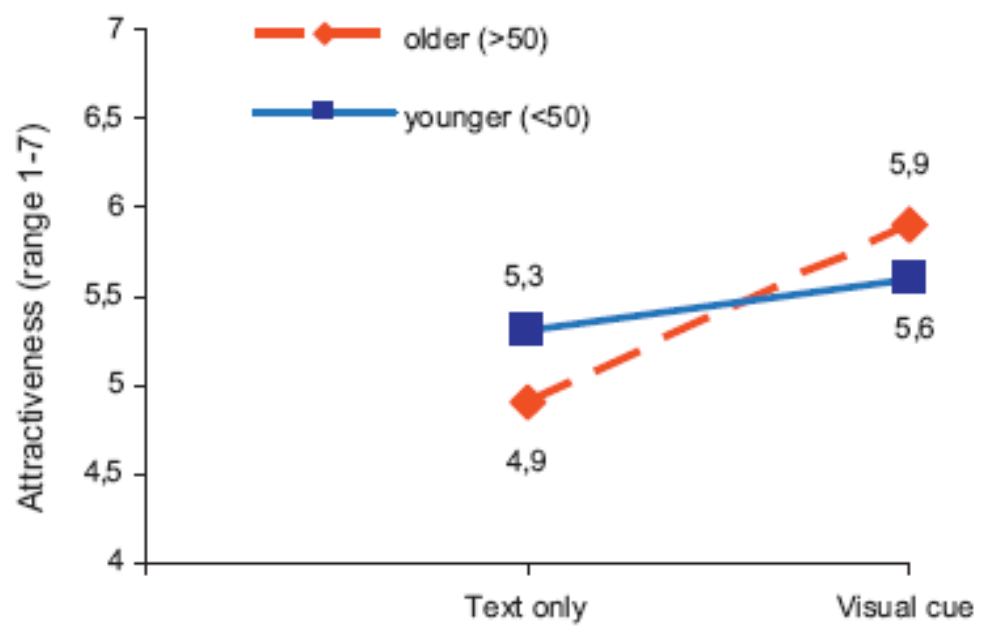

Fig. 9. Age-differences on satisfaction with attractiveness.

Table 3

Table 3

Age effects of language complexity and visual cues on satisfaction $(N=200)$.

\begin{tabular}{|c|c|c|c|c|c|c|c|c|}
\hline & \multicolumn{4}{|c|}{ Satisfaction with comprehensibility } & \multicolumn{4}{|c|}{ Satisfaction with attractiveness } \\
\hline & \multicolumn{2}{|c|}{$<50(n=129)$} & \multicolumn{2}{|c|}{$\geq 50(n=71)$} & \multicolumn{2}{|c|}{$<50(n=129)$} & \multicolumn{2}{|c|}{$\geq 50(n=71)$} \\
\hline & $M$ & SD & $M$ & SD & $M$ & SD & $M$ & SD \\
\hline \multicolumn{9}{|l|}{ Visual cues } \\
\hline Text only $(n=57)$ & 5.34 & 1.01 & $4.92^{2 \cdots}$ & 1.08 & 4.63 & 0.89 & $4.76^{2^{*}}$ & 0.97 \\
\hline Visual cue $(n=143)$ & 5.58 & 1.10 & 5.88 & 1.08 & 4.76 & 0.99 & 5.34 & 1.13 \\
\hline
\end{tabular}

Text only, website without visual cues; visual cue, website with photograph or drawing.

$p<0.05$.

a Significant difference between text only and visual cue. 